\title{
Pilot Results of a Handbook: Prevention Skills of Sexual-Abuse for Primary Students
}

\author{
Son Van Huynh \\ Ho Chi Minh city University of Education \\ Viet Nam \\ Giang Thien $\mathrm{Vu}$ (Correspoing author) \\ Ho Chi Minh city University of Education \\ Viet Nam \\ E-mail: thienvust0708@gmail.com \\ Hanh My Mai \\ Ho Chi Minh city University of Education \\ Viet Nam \\ Huan Thanh Nguyen \\ Ho Chi Minh city University of Education \\ Viet Nam
}

Received: May 7, 2019 Accepted: May 20, 2019 Published: June 11, 2019

doi:10.5296/ijld.v9i2.14757～URL: https://doi.org/10.5296/ijld.v9i2.14757

\begin{abstract}
Child sexual abuse is currently a social condemnation in Vietnam (Giang, T. V., Nguyen, L. B. H. \& Nguyen, P. N. L., 2016). Many educational programs on how to prevent and practice prevention skills against child sexual abuse have been introduced and gained some significant achievements. This article reports the findings on the results of piloting a skill handbook developed for primary students on how to prevent child sexual abuse. The prevention skills
\end{abstract}


were designed as stories and situations. To determine the practicality and effectiveness of the handbook, we collected the opinions of 160 primary students, 35 primary teachers and experts in psychology and education in Ho Chi Minh city. Pilot results showed that $75.1 \%$ of the participating students believed that the handbook was "very good" and "good" For educational, experts and primary teachers, $28.6 \%$ rated the handbook to be very good and $71.4 \%$ to be good. Based on the results, further research has been suggested so that the handbook can be published for use in primary schools in Vietnam in the coming time.

Keywords: handbook, sexual abuse, sexual-abused prevention skills, primary students

\section{Introduction}

Child sexual abuse has been a challenge for many countries in the world. According to the Vietnamese Ministry of Labor, Invalids and Social Affairs (MOLISA), in five years from 2011 to 2015, Vietnam had 5,300 child sexual abuse cases. On average, one child in Vietnam has been being abused every 8 hours (Giang, L. B. H. Nguyen, \& P. N. L. Nguyen, 2016). However, it is believed that the number only indicates the reported cases, and many of the victims were intimidated by the perpetrator, or for some reasons were not reported. In the world, according to the National Society for the Prevention of Cruelty to Children (NSPCC), the average age of sexually abused children is nine years old. One in four girls and six boys has sexually abused. A number of male children being abused tends to increase over years (May, Corinne, \& Cawson. 2005). In Viet Nam, in the past, the abused child was usually 13-18 years old, but the currently reported cases show that they are between 5 and 13, a primary school age (Thanh, 2010).

This paper reports part of a project which develops a handbook for primary school children about how to prevent sexual abuse. Upon completion, the product (the handbook) was evaluated by primary students in Ho Chi Minh City, teachers and experts in the field, which is presented in this article.

Evaluation results from the primary students and experts as well as teachers are important sources to improve the product. Therefore, the pilot of the skills handbook of sexual-abused prevention for primary students is neccessary.

\section{Methods}

To determine the practicality and effectiveness of the handbook, one questionnaire was designed to collect the opinions of 160 primary students, 35 primary teachers and experts in psychology and education. The students and teachers are from two primary schools in Ho Chi Minh City.

The questionnaire consists of five themes: a general evaluation of the handbook, evaluation of quality assessment, of elements related to content and techniques, and criteria for content and form in the handbook. Likert scale was used in the questionnaire with 5 meaning "very good", 4 "good", 3 "average", 2 "weak", and 1 "bad." 


\section{Results}

\subsection{General Assessment of the Handbook}

Table 1 Illustrates the overall evaluation of the handbook by students and teachers.

Table 1. Overall evaluation of the handbook

\begin{tabular}{llllll}
\hline \multirow{2}{*}{ Levels of evaluation } & \multicolumn{2}{l}{ Students' evaluation } & & \multicolumn{2}{l}{ Experts and teachers' evaluation } \\
\cline { 2 - 3 } \cline { 5 - 6 } \cline { 5 - 6 } & Frequency & Percentage & & Frequency & Percentage \\
\hline Very good & 30 & 18.8 & & 10 & 28.6 \\
Good & 90 & 56.3 & & 25 & 71.4 \\
Average & 40 & 25 & & 0 & 0 \\
Weak & 0 & 0 & & 0 & 0 \\
Bad & 0 & 0 & & & \\
\hline
\end{tabular}

Table 1 shows that 30 students $(18.8 \%)$ believed that this is a very good handbook and 90 students $(56.3 \%)$ believed it is a good one, 24 students $(25 \%)$ of the respondents considered it as normal. Thus, among the 160 children surveyed, 120 children commented that it was a good and very good handbook with a $75.1 \% .100 \%$ of the experts and teachers believed that the overall of the handbook is good and very good. Comparing the results from the students' evaluation and teachers' evaluation allows for a conclusion that the handbook has met the expectation of primary school students in a way that the transcript helps them understand the content of sexual abuse prevention. According to The United Nations Children's Fund (UNICEF) in 2012, to develop a child-centered model of care and guidelines to support humanitarian field, staff caring for child survivors of sexual abuse is necessary. Some common tools can be used such as handbooks, flyers, and posters (International Rescue Committee, 2012). The interview results show that, a student (S1), 9 years old, $4^{\text {th }}$ grader, said, "When I received the handbook, I felt very happy and stayed up late until ten o'clock in the evening to read it from a start to the end of the handbook." A student (S2) was able to tell the names of some favorite stories used in the handbook as well as the titles of certain situations. This shows that the handbook's content was designed in a way that is easy for students to remember. Another student (S3), 10 years old, $5^{\text {th }}$ grader, said cheerfully, "I feel that this content is very necessary. The handbook is also useful for children because they can read not only the words but also the illustrated pictures. These kinds of pictures help me remember the prevention skills more clearly and easily."

As for the surveyed experts and teachers, all 35 respondents believed that the handbook has a very good (10) and good (25) form. In other words, $100 \%$ of the respondents said that their first impression of the handbook was good or excellent. According to one expert (E1, psychology expert), "I have counseled on sexual-abused children for many years. When I read this 
handbook, I found that the content is suitable for primary children. Each image and text describe one skill in a very detailed and intuitive way. Children can easily acquire skills through this handbook. It can be said that this handbook is an effective sexual-abused prevention tool to teach children. It should be widely adopted in Vietnam."

Generally, according to the initial assessment of the handbook, it was found that the handbook is good to teach children skills to prevent sexual abuse. From the expert's perspective, this handbook is an effective tool to support skill training as well as providing essential knowledge for at-risk children. From the perspective of primary students' evaluation (end-users), the handbook meets the criteria for the overall evaluation, ensuring the practice of practicing sexual-abused prevention skills for children.

\subsection{Perceived Quality of the Handbook}

Table 2 shows the results on the quality of the handbook perceived by students and teachers and experts.

Table 2. Evaluation of the quality of the skills handbook

\begin{tabular}{|c|c|c|c|c|c|c|c|c|}
\hline \multirow{2}{*}{ Factors } & \multicolumn{4}{|c|}{ Students' evaluation (\%) } & \multicolumn{4}{|c|}{$\begin{array}{l}\text { Experts and teachers' evaluation } \\
(\%)\end{array}$} \\
\hline & $\begin{array}{l}\text { Very } \\
\text { good }\end{array}$ & Good & Average & Mean & $\begin{array}{l}\text { Very } \\
\text { good }\end{array}$ & Good & Average & Mean \\
\hline Images & 62.5 & 25 & 12.5 & 4.5 & 28.6 & 71.4 & 0 & 4.71 \\
\hline Colors & 62.5 & 18.8 & 18.8 & 4.43 & 14.3 & 42.9 & 42.9 & 4.28 \\
\hline Word form & 43.8 & 43.8 & 12.5 & 4.31 & 14.3 & 42.9 & 42.9 & 4.28 \\
\hline The coverage of the content & 75 & 18.8 & 0 & 4.8 & 14.3 & 28.6 & 57.1 & 4.42 \\
\hline The perspicuity & 50 & 50 & 0 & 4.5 & 71.4 & 28.6 & 0 & 4.71 \\
\hline Application of the content & 56.3 & 25 & 18.8 & 4.37 & 57.1 & 28.6 & 14.3 & 4.42 \\
\hline $\begin{array}{l}\text { Suitability for primary } \\
\text { students }\end{array}$ & 68.8 & 31.3 & 0 & 4.68 & 85.7 & 14.3 & 0 & 4.71 \\
\hline
\end{tabular}

The results show that the students rated the quality of all the factors in the handbook to be very good (a mean of all factors above 4.3). Four aspects which were evaluated highest were:

- $\quad$ The coverage of the content (4.8)

- Suitability for primary students (4.68)

- The comprehension of the content (4.5)

- $\quad$ Images (4.5)

According to Klaus M. Beier, prevention strategies include research on individuals at risk to 
commit first or persistent sexual offenses against children, at the same time offering preventive assessment and treatment. It will be shown that these groups are reachable (given that they can rely on anonymity and the professional pledge of confidentiality) to improve the prevention of child sexual abuse, because sexually deviant interests have been identified as a major risk factor for first or persistent sexual offending against children. Therefore, public health services or composing a handbook have a real chance of encouraging the concerned persons to seek professional help before any kind of sexual offense against children is committed (Klaus M. Beier, 2016).

Before evaluating the quality of the handbook, we conduct research on the necessary content to equip primary students with sexual-abused prevention skills. The results show that identifying dangerous signs and unsafe situations through pictures is the most effective way to convey the message of sexual-abused prevention in accordance with the psychological characteristics of the children (Giang, T. V., Nguyen, L. B. H., \& Nguyen, P. N. L., 2016). Therefore, the reason primary students appreciate is that the content of the handbook is based on the result from the survey of primary school students' perceptions of the contents of the abuse prevention and the content that the group is most interested.

In other words, the contents presented in the handbook are the four elements proposed by the primary school students. However, there are some ideas that the handbook has not conveyed what students are interested. One student (S4), 10 years old, found that the content of one lesson/skill entitled "You want to be safe and happy" is too short.

The second highest rated item is "suitability for primary students". The suitability is expressed by the following requirements: in accordance with the physiological characteristics of primary students, using situations commonly encountered by primary students in practice, their daily activities. Compared with the requirements that these students made during the first survey, they asked for the "best method" they were most interested in. The student's appreciation of the "Suitable for primary school students" element is a testimony to the fact that the handbook has been developed in accordance with the object and object of the research project that is dedicated to the blind student. This factor is also highly appreciated by experts and teachers.

The third is "image" and "The comprehension of the content" with an average score of 4.5. These factors are also highly appreciated by experts and teachers. Teacher 1 (T1, the head of Thien An shelter), remarked: "In general, the pictures shown in the brochure are very good, the images are easy to see, attached to elementary students and oriented towards behavior and emotions of the children with the theme without shield or too much".

The other three elements are "color", "applicability of content", "usage and word expression", although the average score is lower than the above factors but still evaluated at pretty good. None of the factors are rated average, weak and bad according to the established scale.

According to expert 2 (E2, psychology expert), "The form of the handbook is very lively, clear picture, beautiful color and layout. In terms of content, the creative idea of the handbook is based on the scientific value of child sexual-abuse studies, with the introduction of problematic situations, followed by trial case handling, suggestive treatment situations, memories and 
emotional experiences, is a good idea, close to primary students. The content is the specific situation and the solution to each specific situation associated with the lessons learned from those situations perfectly suited to the psychological development characteristics of primary students."

Compared with research of WHO Regional Office for Europe about the Measuring and monitoring national prevalence of child maltreatment: a practical handbook, which suggests community-based surveys on prevalence as the most appropriate method in setting up a child maltreatment surveillance system and proposes the use of one of three established child maltreatment questionnaires, based on the results of a rapid systematic review of child abuse measures (F. Meinck, J. I. Steinert, D. Sethi, R. Gilbert, M. A. Bellis, C. Mikton, L. Alink \& A. Baban, 2016). The quality of the elements in this handbook is generally good and can be widely used with primary students, although there are some shortcomings.

\subsection{Evaluate Factors Related to Content and Techniques in the Skill of Sexual-Abused Prevention Handbook for Primary Students}

Table 3. Evaluation of factors related to content and techniques in the abuse prevention skills handbook for primary school students.

\begin{tabular}{lll}
\hline \multirow{2}{*}{ Factors } & \multicolumn{2}{l}{ Percentage } \\
\cline { 2 - 3 } & Students' evaluation & Experts and Teachers' evaluation \\
\hline Cover sheet & 81 & 71.4 \\
Composition of items, sections & 100 & 85.7 \\
The division of the article & 81.3 & 57.1 \\
The demonstration & 81.3 & 100 \\
Total volume of handbook & 81.3 & 71.4 \\
The art of content & 87.5 & 100 \\
The science of content & Not examined & 85.7 \\
The education of the content & 93.8 & 85.7 \\
The creativity of performance & 87.5 & 71.4 \\
\hline
\end{tabular}

According to the survey of teachers and experts, $71.4 \%$ of the respondents said that the handbook was satisfactory, but some teachers said that the handbook was slightly simplified. Another factor is the "scientific nature of the content". We do not survey students on this factors because they will find it difficult to assess the correctness of knowledge, an important component of scientific inquiry. As many as $85.7 \%$ of teachers and experts think the handbook has achieved this. That proves that nearly $9 / 10$ teachers and experts acknowledge the correctness and reliability of the content. This signal is very good for an educational product. 
Based on the data in table 3, all factors of the handbook are appreciated by the students and teachers, experts (almost $60 \%$ up to 100\%). The "Composition of items, sections" was highlighted by all students in the survey (100\%), making up the absolute percentage. To explain this ratio, we conducted an interview with one student (S5), 5th grader, who said that the division and ordering of the articles in the manual made it easy for them to understand very consistent and continuous. In addition, $85.7 \%$ of teachers said that this factor was satisfactory, a high figure ranked second among the surveyed factors. It can be that the determination of the content from easy to difficult, from general to specific, from sex physiology to sex psychology and finally the social issues of sex create a tight structure and logic for the handbook. This factor is highly appreciated as a demonstration of how the handbook can be used to equip students with knowledge and skills to prevent abuse outside the classroom.

Second is "The education of the content" with a $93.8 \%$ selectivity rate and a $85.7 \%$ teacher-expert rating. This result is reflected in the process of building the content structure has identified the specific purpose, selecting the content and method of means to achieve the optimal effect when applied. Also, since this is a handbook that is of a supportive nature, so in addition to the students feel that the content can provide the knowledge and skills of sexual-abused prevention. This factor of teachers and experts' appreciation has shown the applicability of the handbook in the school setting. According to expert 3 (E3, psychology expert): "The handbook is quite close and practical. We can say the content is very useful and practical. We like the way the issue and the presentation of this handbook are ...".

The factor considered by the students to be in the third grade is "The art of content" and "The creativity of performance". On the "The art of content", it is not only the effect of this factor highly appreciated by students, but also by the sheer number of teachers. A four-part sexual-abused prevention education handbook offers a variety of expressions that make students feel very excited. Therefore, it can be concluded that the factor of art in the handbook corresponds to the excitement characteristics of primary students. On the "The creativity of performance", in general, all the subjects consider the handbook to achieve this. In addition, teachers and experts were more rigorous in the evaluation $(71.4 \%)$, but the variance was not too high. A teacher (T2, primary school teacher) said: "When reading the handbook, my first feeling is the novel, I heard it when the adults say but listen here still feel different and attractive, I remember long time". With the students' opinions, teachers and experts agree that creativity is reflected in the fact that the selected form is well suited to the content and is "processed" very flexible.

Placed next are three factors with the same ratio of $81.3 \%$ of the students choose to be "The division of the article", "The demonstration", and "Total volume of handbook". The same percentage of students chooses the same, but the factor of "The demonstration" is the whole teacher and experts appreciate. In general, the view that the individual performance, in part, is consistent with the characteristics of primary students and psychological characteristics of the age.

In short, the first product cannot avoid certain limitations. However, the pilot results of the handbook initially achieved is extremely positive. Most importantly, the handbook has the 
essential requirements an educational support product needs. Finishing and modifying the handbook only requires some content to make the handbook product more effective and a powerful tool to support effective prevention and control. These are also important bases for the handbook to become a documented prevention education published to help protect primary students from the risks of sexual-abused.

\section{Conclusion}

The survey results show that almost all participants think that the general evaluation of the handbook is good and very good. In addition, comments on quality, relevant factors and some specific criteria in the handbook gained high level of support and consensus. In addition, the results of the survey also brought some respectable comments from students, teachers and experts to make the handbook better. It can be said that the sexual-abused prevention handbook for primary school students is a humanistic solution in the education, especially education prevention against sexual-abused of primary students in Vietnam theseday.

\section{Acknowledgement}

This work was supported by Ho Chi Minh City University of Education and the product was published by Ho Chi Minh City University of Education Press in 2017, named The handbook skills for sexual-abused prevention of primary school students.

\section{References}

Aarti, K. \& Afrooz, K. J. (2014). Sexual Abuse Prevention. Copyright of World Vision Vietnam.

Beier, K. M. (2016). Proactive strategies to prevent child sexual abuse and the use of child abuse images: Experiences from the German Dunkelfeld Project. In Women and children as victims and offenders: Background, prevention, reintegration (pp. 499-524). Springer, Cham. https://doi.org/10.1007/978-3-319-28424-8_19

Bethany, H. (2018). Primary school principal faces child sex assault charges. The West Australian.S

Dao, V. C. (2002). Situation and measures of sex education for pupils in some high schools in District 2, Ho Chi Minh City. Graduation thesis. HCMC University of Education.

Francoise, D., Catherine, D. T. \& Colette, P. (2004). Speaking of adolescence. Van Anh (translation). Youth Publisher.

Meinck, F., Steinert, J., Sethi, D., Gilbert, R., Bellis, M., Alink, L., \& Baban, A. (2016). Measuring and monitoring national prevalence of child maltreatment: a practical handbook.

Giang, T. V., Nguyen, L. B. H. \& Nguyen, P. N. L. (2016). Feeling-lifted solutions for sexual-abused children. Science research study of Ho Chi Minh city University of Education.

Gillian C. Mezey. (2000). Male Victims of Sexual Assault. Oxford University Press.

Huynh, V. S. and Dao, L. H. A. (2013). Conversation with Dr Deer. Youth Publisher. 


\section{Macrothink}

International Journal of Learning and Development

ISSN 2164-4063 2019, Vol. 9, No. 2

International Rescue Committee. (2012). The Caring for Child Survivors (CCS) of Sexual Abuse Guidelines. 1st Edison. USA: New York.

Jenny, P. (2002). The Trauma of Sexual Assault: Treatment, Prevention and Practice. John Wiley and Sons Ltd.

Laura K. M., Amanda Nguyen \& Judith, A. C. (2012). Child Sexual Abuse. World Health Organization (WHO).

Le, V. H. (2009). Psychology of age and pedagogical psychology. Ha Noi: Hanoi National University Publisher.

Le, T. M. T. (2013). Access to Cognitive Behavioral Therapy Coordination between theory and practice. Ho Chi Minh city: Publisher of Times.

May-Chahal, C., \& Cawson, P. (2005). Measuring child maltreatment in the United Kingdom: A study of the prevalence of child abuse and neglect. Child abuse \& neglect, 29(9), 969-984. https://doi.org/10.1016/j.chiabu.2004.05.009

Ministry of Education and Training. (2005). Learn the law of education 2005. Educational Publisher.

Nguyen, V. H. (2002). Teaching theories. Education Publishing House.

Pham, T. H. (2011). Life skills: Who are you. Vietnamese Education Publisher.

Thanh, B. (2010). Egypt argues about sex education at school. Vietnam+ Newspaper.

Tran, N. G. \& Le, V. T. (2010). Integrated education management. Women's Publisher.

Vu, D. (2008). Dictionary of Psychology. Dictionary of Encyclopedia Press.

\section{Copyright Disclaimer}

Copyright for this article is retained by the author(s), with first publication rights granted to the journal.

This is an open-access article distributed under the terms and conditions of the Creative Commons Attribution license (http://creativecommons.org/licenses/by/4.0/). 